\title{
Intrauterine Growth Restriction
}

\author{
*Heshmat SW Haroun \\ Professor of Anatomy and Embryology, Faculty of Medicine, Cairo University, Egypt
}

Submission: March 07, 2017; Published: March 16, 2017

*Corresponding author: Heshmat SW Haroun, Professor of Anatomy and Embryology, Faculty of Medicine, Cairo University, Giza, Egypt, Email: heshmatsabet@gmail.com

\begin{abstract}
Intrauterine growth restriction (IUGR) is considered the most common cause of low birth weight or small for gestational age (SGA) birth. When the maternal environment during pregnancy is perturbed, from events such as hypoxia, stress, toxins, inflammation, and placental hypo perfusion, impaired fetal development will result. The main underlying mechanism of IUGR is chronic placental insufficiency that interrupts oxygen and nutrients supply to the fetus resulting in an abnormal fetal growth; the placenta shows functional and structural changes. IUGR is either symmetrical or asymmetrical. It is a major cause of perinatal morbidity and mortality. The condition is frequently associated with neurodevelopment, metabolic and cardiovascular impairments early in infancy and late in adulthood.
\end{abstract}

Keywords: Intrauterine growth restriction; Small for gestational age; Mechanism; Risk factors; Neurodevelopmental impairment; Cardiovascular Outcomes.

Abbreviations: AFP: Alpha-Fetoprotein; AGA: Appropriate for Gestational Age; CHD: Congenital Heart Disease; EPCs: Endothelial Progenitor Cells; FGR: Fetal Growth Restriction; HC: Head Circumference; HCQ: Hydroxychloroquine; HGR: Head Growth Restriction; IUGR: Intrauterine Growth Restriction; mt: Mitochondrial; NAS: Neonatal Abstinence Syndrome; NE: Norepinephrine; NIMs: Neural Injury Markers; NRF1: Nuclear Respiratory Factor 1; NSE: Neuron-Specific Enolase; pMSCs: Placental Mesenchymal Stromal Cells; RCC: Respiratory Chain Complexes; SGA: Small for Gestational Age; SGR: Symmetrical Growth Restriction; SLE: Systemic Lupus Erythematosus; WGR: Weight Growth Restriction

\section{Introduction}

Intrauterine growth restriction (IUGR), also known as "intrauterine growth retardation" or "fetal growth restriction", is a term applied to a condition of poor growth of the fetus in utero. The condition results in an "infant small for date" or "dysmature infant" that is defined as having a weight at or below the 10th percentile for the expected birth weight at a given gestational age [1]. The prevalence of low birth weight caused either by preterm birth or by IUGR, is reported to be $3-10 \%$ of live newborns in developed countries and $15-20 \%$ of newborns in developing countries [2]. Fetuses at risk for IUGR are susceptible to potential intrauterine environment that leads to fetal hypoxia and fetal acidosis [3]. Late-onset IUGR issues from failure of the placenta to supply adequate nutrients and oxygen to the rapidly growing fetus [4]. High amniotic fluid erythropoietin concentration reflects chronic fetal hypoxia and is associated with decreased umbilical artery $\mathrm{pH}$ and with adverse neonatal outcome in IUGR before 34 gestational weeks [5]. Fetal growth restriction (FGR) represents an obstetrical complication that would amount to about $10 \%$ of fetuses in the general population [6]. IUGR is considered the main cause of intrauterine fetal death and the second leading cause of death in neonates; it seems that females are more prone to develop IUGR [7].

\section{Etiology, Risk factors and Diagnostic Measures}

Optimal fetal growth is a multifactorial process whose mechanism has not yet been fully elucidated. Uteroplacental insufficiency plays a major role in the etiology of IUGR. The major risk factors for IUGR and small for gestational age (SGA) births include chromosomal abnormalities, congenital infectious diseases, poor maternal health (diabetes mellitus, hypertension, anemia, cardiac, renal and hepatic diseases), preeclampsia, smoking, environmental pollutants, drug and alcohol abuse, maternal age above 35 years, and placental pathologies (infarction, fetal vessel thrombosis, and chronic villitis). Other risk factors are multiple pregnancy, primiparity, maternal malnutrition, and low socioeconomic status. Zinc sulfate feeding, of mercury-exposed pregnant rats, could correct the reduced placental weight, fetal weight and size, and tail length induced by mercury exposure [8]. SGA is associated with a four-fold increased risk of stillbirth as well as higher rates of cesarean and induced labor before 37 weeks [9-11]. 
Proper maternal nutrition maintains birth weight mainly through the modulation of placental lipid and energy metabolism [12]. Amino acids promote fetal growth through building up of proteins and regulation of the metabolic pathways in fetoplacental development. During pregnancy, dietary supplementation with functional amino acids (as arginine and glutamine) has a great role in prevention of IUGR [13]. Aspirin when used with omega 3 is mentioned to be more effective, than using aspirin alone, in increasing fetal weight and improving utero-placental blood flow in asymmetrical IUGR [14]. Selenium supplementations are also reported to improve the clinical and metabolic status in pregnant women at risk for IUGR [15].

There is a well-known association of early maternal primiparity age with smaller children, particularly in developing countries. It is unclear whether this small pregnancy outcome is due to the age at which child growth restriction first occurs or due to other factors such as socioeconomic status [16].

Risk factors for IUGR are easy to assess but they have poor predictive value. Modern methods of assessment of IUGR include serum biomarkers, ultrasound and Doppler study of the uterine and spiral arteries, the placental volume and placental vasculature [17]. If a reliable prediction could be achieved, there will be a potential to reduce future perinatal morbidity, mortality and long-term consequences; however measures have to be better directed toward the prevention of IUGR [18].

Proper structure of the umbilical cord is important for the fetal development. Exposure to tobacco smoke was found to have a negative impact on fetal growth and umbilical cord morphometry and to correlate with intensity of IUGR. Wharton's jelly of cords of offsprings born to smoker women was increased when compared to nonsmokers [19-21]. Alcohol administration, in mice, was found to perturb polyamine levels in embryonic and extra embryonic tissues. The total absence of polyamines in the mouse embryo head might explain the development of neural tube defect, and growth restriction. These findings were similar to those observed in fetal alcohol syndrome [22]. Opioids whether prescribed to or illegally consumed by pregnant women are associated with numerous complications including IUGR, and increased risk of neonatal mortality and neonatal abstinence syndrome (NAS) [23].

In women suffering from systemic lupus erythematosus (SLE), it has been observed that treatment with hydroxychloroquine (HCQ) reduces neonatal morbidity by significantly decreasing the rate of prematurity and IUGR [24]. Placental insufficiency is associated with fetal hypoglycemia, hypoxemia, and elevated plasma norepinephrine (NE) leading to IUGR. In pregnant ewes, it was observed that NE, independently of hypoxemia, hypoglycemia and hypoinsulinemia, had influenced asymmetry of growth but not pancreatic $\beta$ - and $\alpha$-cell masses in IUGR fetuses [25]. Nesfatin 1 is a neuropeptide formed in hypothalamus of mammals and is known to regulate hunger and lipid storage. It may have a possible role in controlling fetal growth [26].

\section{Placental Histopathology in IUGR}

Abnormal placentation is responsible for most of gestational disorders [27]. The histopathological features exhibited by the placentas of pregnancies with early IUGR include infarction, chronic villitis, chronic chorio-amnionitis, membrane necrosis, increased nucleated red blood cells, increased syncytial knotting, increased villous maturation, and fetal thrombosis [28]. Decreased endothelial differentiation and increased adipocte differentiation potentials, exerted by the human placental mesenchymal stromal cells (pMSCs), have been demonstrated in placentas with IUGR [29]. Assessment of mitochondrial (mt) DNA and nuclear respiratory factor 1 (NRF1) expression in placental tissue and cytotrophoblast cells, gene and protein expressions of respiratory chain complexes (RCC) could be helpful indices for IUGR and other gestational disorders [30,31]. Endothelial progenitor cells (EPCs) play a principal role during pregnancy by maintaining adequate placentation and fetal growth. In maternal blood their count is progressively increased in normal pregnancy; being detectable in early pregnancy but more elevated in the third trimester. The increase of EPCs is impaired in IUGR-complicated pregnancies [32].

The fetoplacental vasculature and resistance are uniquely not regulated by autonomic elements but by humoral mediators, most of which are synthesized by the local fetoplacental endothelial cells. In IUGR pregnancies, the production of these mediaors is impaired favoring vasoconstriction. Moreover, placentas from these pregnancies are structurally deviated from the normal placental morphology revealing abnormal branching, thinning, and elongation of the vessels within the terminal functioning chorionic villi; thus elevating the fetoplacental vascular resistance [33].

\section{Outcomes and Associations of IUGR}

Sonography has revealed that IUGR is associated with involution of the size of the fetal thymus gland. A small fetal thymus is considered as an early indicator of adverse perinatal outcomes [34]. Ovine fetuses, with IUGR, exhibited decreased thymic weight with diminution of its cortical thickness as well as reduced DNA content and total antioxidant capacity. These changes were assumed to be indicators of reduced cell proliferation, oxidative stress, and increased cell apoptosis for impaired development of IUGR fetal thymus [35]. In another study, 2D and 3D ultrasonography showed that fetal thymus transverse and anteroposterior diameters, and volume had increased with normal advance of gestational weeks. In IUGR, these parameters were less than those of the same gestational age fetal thymus [36].

IUGR increases the risk of neurodevelopment impairment during childhood [37]. The fetal brain is particularly vulnerable in IUGR and there is an increased risk of long-term neurological disorders including cerebral palsy, epilepsy, learning and behavioral difficulties as well as psychiatric conditions [38]. 
In late-onset IUGR, functional and morphological brain disturbances develop earlier before compensatory blood flow redistribution towards the fetal brain, as detected by Doppler measurements between the fetal brain (in the middle cerebral artery) and the placenta (in the umbilical artery) [39]. Some researchers have demonstrated that even mild intrauterine hypo perfusion could alter neurological development in a way that resembles the clinical picture of neurodevelopment disorders in children born prematurely or with IUGR [40]. In IUGR, three neural injury markers (NIMs): s100B, neurone-specific enolase (NSE) and alpha-fetoprotein (AFP) in umbilical arterial, umbilical venous and maternal venous sera are used as predictors of neonatal complications [41]. Symmetrical growth restriction (SGR), in preterm infants, is associated with neonatal mortality and impaired cognitive function and school performance. The outcome of asymmetrical growth restriction differs according to head circumference (HC). Head growth restriction (HGR) is associated with impaired cognitive function while weight growth restriction (WGR) is not [42]. Furthermore, changes in the concentration of neurotransmitters: catecholamines and indoleamines were demonstrated at the hypothalamus of swine fetuses affected by nutrient shortage [43]. In MRI scans of growth-restricted preterm infants, thalamus and basal ganglion were observed to be reduced in volume with the risk for neurodevelopmental impairment [44].

Low birth weight, caused by either preterm birth or IUGR, is associated with increased rates of short and long-term renal and cardiovascular diseases. IUGR fetuses experience cardiovascular remodeling that persists into infancy and is related to hypertension and cardiovascular diseases in adulthood [45]. Several studies have demonstrated changes in the structure and function of the heart in fetuses with IUGR [46]. Neonates with symmetrical or asymmetrical IUGR had revealed reduced left ventricular dimensions, thickness and mass when compared with appropriate for gestational age (AGA) neonates; left ventricular systolic functions were mostly preserved [47]. On the contrary, in other studies IUGR fetuses have shown larger and more globular hearts together with signs of systolic and diastolic dysfunction [48]. Persistence of significantly higher abdominal aortic intima-media thickness and microalbuminuria during infancy is another association of IUGR [49]. Cases with isolated fetal congenital heart disease (CHD) have a great risk to develop IUGR [50]. Maternal gestational hypercholesterolemia and atherosclerosis in mice were also associated to early onset fetal growth restriction. Dietary vitamin E supplementation had a beneficial impact on this condition [51]. Utmost care and measures have to be undertaken to predict the risk factors of IUGR in order to lessen the related perinatal morbidity and mortality.

\section{References}

1. Sadler TW, Thomas W, Lanmgan J (2010) Langman's Medical Embryology. Wolters Kluwer, Lippincott Williams \& Wilkins, Philadelphia, Pennsylvania, USA, pp. 1-385.
2. Radon Pokracka M, Huras H, Jach R (2015) Intrauterine growth restriction-diagnosis and treatment. Przegl Lek 72(7): 376-382.

3. Zelop CM, Javitt MC, Glanc P, Dubinsky T, Harisinghani MG, et al. (2013) ACR Appropriateness Criteria ${ }^{\circledR}$ growth disturbances - risk of intrauterine growth restriction. Ultrasound Q 29(3): 147-151.

4. Zhu MY, Milligan N, Keating S, Windrim R, Keunen J, et al. (2016) The hemodynamics of late-onset intrauterine growth restriction by MRI. Am J Obstet Gynecol 214(3): 367.

5. Seikku L, Rahkonen L, Tikkanen M, Hamalainen E, Rahkonen P, et al. (2015) Amniotic fluid erythropoietin and neonatal outcome in pregnancies complicated by intrauterine growth restriction before 34 gestational weeks. Acta Obstet Gynecol Scand 94(3): 288-294.

6. Lausman A, Kingdom J, Gagnon R, Basso M, Bos H, et al. (2013) Intrauterine growth restriction: screening, diagnosis, and management. Gynaecol Can 35(8): 741-757.

7. Radulescu L, Ferechide D, Popa F (2013) The importance of fetal gender in intrauterine growth restriction. J Med Life 6(1): 38-39.

8. Weng Z, Liu Z, Zhang S, Tao H, Ji X (2017) Zinc protection in fetal rats for maternal mercury exposure-induced growth retardation is probably associated with S100B expression. J Obstet Gynaecol Res 43(1): 73-77.

9. Gaudineau A (2013) Prevalence, risk factors, maternal and fetal morbidity and mortality of intrauterine growth restriction and smallfor-gestational age. J Gynecol Obstet Biol Reprod 42(8): 895-910.

10. Sato Y, Benirschke K, Marutsuka K, Yano Y, Hatakeyama K, et al. (2013) Associations of intrauterine growth restriction with placental pathological factors, maternal factors and fetal factors; clinicopathological findings of 257 Japanese cases. Histol Histopathol 28(1): 127-132.

11. Al Gubory KH (2016) Multiple exposures to environmental pollutants and oxidative stress: Is there a sex specific risk of developmental complications for fetuses? Birth Defects Res C Embryo Today 108(4): 351-364.

12. Che L, Yang Z, Xu M, Xu S, Che L, et al. (2017) Maternal nutrition modulates fetal development by inducing placental efficiency changes in gilts. BMC Genomics 18(1): 213.

13. Lin G, Wang $X$, Wu G, Feng C, Zhou H, et al. (2014) Improving amino acid nutrition to prevent intrauterine growth restriction in mammals. Amino Acids 46(7): 1605-1623.

14. Ali MK, Amin ME, Amin AF, Abd El Aal DE (2017) Evaluation of the effectiveness of low-dose aspirin and omega 3 in treatment of asymmetrically intrauterine growth restriction: A randomized clinical trial. Eur J Obstet Gynecol Reprod Biol 210: 231-235.

15. Mesdaghinia E, Rahavi A, Bahmani F, Sharifi N, Asemi Z (2016) Clinical and Metabolic Response to Selenium Supplementation in Pregnant Women at Risk for Intrauterine Growth Restriction: Randomized, Double-Blind, Placebo-Controlled Trial. Biol Trace Elem Res pp. 1-8.

16. Yu SH, Mason J, Crum J, Cappa C, Hotchkiss DR, et al. (2016) Differential effects of young maternal age on child growth. Glob Health Action 9(1): 31171.

17. Albu AR, Anca AF, Horhoianu VV, Horhoianu IA (2014) Predictive factors for intrauterine growth restriction. J Med Life 7(2): 165-71.

18. Salam RA, Das JK, Bhutta ZA (2014) Impact of intrauterine growth restriction on long-term health. Curr Opin Clin Nutr Metab Care 17(3): 249-254.

19. Milnerowicz Nabzdyk E, Bizon A (2015) How does tobacco smoke influence the morphometry of the fetus and the umbilical cord?Research on pregnant women with intrauterine growth restriction exposed to tobacco smoke. Reprod Toxicol 58: 79-84. 
20. Milnerowicz Nabzdyk E, Bizon A (2014) Effect of cigarette smoking on vascular flows in pregnancies complicated by intrauterine growth restriction. Reprod Toxicol 50: 27-35.

21. Banderali G, Martelli A, Landi M, Moretti F, Betti F, et al. (2015) Short and long term health effects of parental tobacco smoking during pregnancy and lactation: a descriptive review. J Transl Med 13: 327.

22. Haghighi Poodeh S, Alhonen L, Salonurmi T, Savolainen MJ (2014) Ethanol-induced impairment of polyamine homeostasis--a potential cause of neural tube defect and intrauterine growth restriction in fetal alcohol syndrome. Biochem Biophys Res Commun 446(1): 173-178.

23. Stover MW, Davis JM (2015) Opioids in pregnancy and neonatal abstinence syndrome. Semin Perinatol 39(7): 561-565.

24. Leroux M, Desveaux C, Parcevaux M, Julliac B, Gouyon JB, et al. (2015) Impact of hydroxychloroquine on preterm delivery and intrauterine growth restriction in pregnant women with systemic lupus erythematosus: a descriptive cohort study. Lupus 24(13): 1384-1391.

25. Davis MA, Macko AR, Steyn LV, Anderson MJ, Limesand SW (2015) Fetal adrenal demedullation lowers circulating norepinephrine and attenuatesgrowth restriction but not reduction of endocrine cell mass in an ovine model of intrauterine growth restriction. Nutrients 7(1): 500-516.

26. Serin S, Bakacak M, Ercan O, Kostu B, Avci F, et al. (2016). The evaluation of Nesfatin-1 levels in patients with and without intrauterine growth restriction. Matern Fetal Neonatal Med 29(9): 1409-1413.

27. Siauve N, Chalouhi GE, Deloison B, Alison M, Clement O, et al. (2015) Functional imaging of the human placenta with magnetic resonance. Am J Obstet Gynecol 213: S103-114.

28. Veerbeek JH, Nikkels PG, Torrance HL, Gravesteijn J, Post Uiterweer ED, et al. (2014) Placental pathology in early intrauterine growth restriction associated with maternal hypertension. Placenta 35(9): 696-701.

29. Mando C, Razini P, Novielli C, Anelli GM, Belicchi M, et al. (2016). Impaired Angiogenic Potential of Human Placental Mesenchymal Stromal Cells in Intrauterine Growth Restriction. Stem Cells Transl Med 5(4): 451-463.

30. Mando C, De Palma C, Stampalija T, Anelli GM, Figus M, et al. (2014) Placental mitochondrial content and function in intrauterine growth restriction and preeclampsia. Am J Physiol Endocrinol Metab 306(4): E404-413.

31. Holland O, Dekker Nitert M, Gallo LA, Vejzovic M, Fisher JJ, et al. (2016) Review: Placental mitochondrial function and structure in gestational disorders. Placenta pii:S0143-4004(16)30659-2.

32. Calcaterra F, Taddeo A, Colombo E, Cappelletti M, Martinelli A, et al. (2014). Reduction of maternal circulating endothelial progenitor cells in human pregnancies with intrauterine growth restriction. Placenta 35(7): 431-436

33. Su EJ (2015) Role of the fetoplacental endothelium in fetal growth restriction with abnormal umbilical artery Doppler velocimetry. Am J Obstet Gynecol 213: S123-130.

34. Ekin A, Gezer C, Taner CE, Solmaz U, Gezer NS, et al. (2016) Prognostic Value of Fetal Thymus Size in Intrauterine Growth Restriction. J Ultrasound Med 35(3): 511-517.

35. Liu Y, He S, Zhang Y, Xia W, Li M, et al. (2015) Effects of Intrauterine Growth Restriction During Late Pregnancy on the Development of the Ovine Fetal Thymus and the T-Lymphocyte Subpopulation. Am J Reprod Immunol 74(1): 26-37.

36. Yang R, Guo F, Liu X, Tian J, Fan L (2014) Application of two and three-dimensional ultrasound measurement of fetal thymus in fetal intrauterine growth restriction. Zhonghua Yi Xue Za Zhi 94(33): 26072609.

37. Murray E, Fernandes M, Fazel M, Kennedy SH, Villar J, et al. (2015) Differential effect of intrauterine growth restriction on childhood neurodevelopment: a systematic review. BJOG 122(8): 1062-1072.

38. Wixey JA, Chand KK, Colditz PB, Bjorkman ST (2016) Review: Neuroinflammation in intrauterine growth restriction. Placenta pii: S0143-4004(16)30642-7.

39. Starcevic M, Predojevic M, Butorac D, Tumbri J, Konjevoda P, et al. (2016) Early functional and morphological brain disturbances in lateonset intrauterine growth restriction. Early Hum Dev 93: 33-38.

40. Ohshima M, Coq JO, Otani K, Hattori Y, Ogawa Y, et al. (2016) Mild intrauterine hypoperfusion reproduces neurodevelopmental disorders observed in prematurity. Sci Rep 6: 39377.

41. Velipasaoglu M, Yurdakok M, Ozyuncu O, Portakal O, Deren 0 (2015). Neural injury markers to predict neonatal complications in intrauterine growth restriction. J Obstet Gynaecol 35(6): 555-560.

42. Guellec I, Marret S, Baud O, Cambonie G, Lapillonne A, et al. (2015) Intrauterine Growth Restriction, Head Size at Birth, and Outcome in Very Preterm Infants. J Pediatr 167(5): 975-981.

43. Garcia Contreras C, Valent D, Vazquez Gomez M, Arroyo L, Isabel B, et al. (2017) Fetal growth-retardation and brain-sparing by malnutrition are associated to changes in neurotransmitters profile. Int J Dev Neurosci 57: 72-76.

44. Bruno CJ, Bengani S, Gomes WA, Brewer M, Vega M, et al. (2017) MRI Differences Associated with Intrauterine Growth Restriction in Preterm Infants. Neonatology 111(4): 317-323.

45. Cruz Lemini M, Crispi F, Valenzuela Alcaraz B, Figueras F, Gomez O, et al. (2014) A fetal cardiovascular score to predict infant hypertension and arterial remodeling in intrauterine growth restriction. Am J Obstet Gynecol 210(6): 552.

46. Niewiadomska Jarosik K, Zamojska J, Zamecznik A, Wosiak A, Jarosik $\mathrm{P}$, et al. (2016) Myocardial dysfunction in children with intrauterine growth restriction: an echocardiographic study. Cardiovasc J Afr 28(1): 36-39.

47. Cinar B, Sert A, Gokmen Z, Aypar E, Aslan E, et al. (2015) Left ventricular dimensions, systolic functions, and mass in term neonates with symmetric and asymmetric intrauterine growth restriction. Cardiol Young 25(2): 301-307.

48. Perez Cruz M, Cruz Lemini M, Fernandez MT, Parra JA, Bartrons J, et al. (2015) Fetal cardiac function in late-onset intrauterine growth restriction vs small-for-gestational age, as defined by estimated fetal weight, cerebroplacental ratio and uterine artery Doppler. Ultrasound Obstet Gynecol 46(4): 465-471.

49. Zanardo V, Fanelli T, Weiner G, Fanos V, Zaninotto M, et al. (2011) Intrauterine growth restriction is associated with persistent aortic wall thickening and glomerular proteinuria during infancy. Kidney Int 80(1): 119-123.

50. Wallenstein MB, Harper LM, Odibo AO, Roehl KA, Longman RE et al. (2012) Fetal congenital heart disease and intrauterine growth restriction: a retrospective cohort study. J Matern Fetal Neonatal Med 25(6): 662-665.

51. Busso D, Mascareno L, Salas F, Berkowitz L, Santander N, et al. (2014) Early onset intrauterine growth restriction in a mouse model of gestational hypercholesterolemia and atherosclerosis. Biomed Res Int p. 11. 
(C) This work is licensed under Creative (1) Commons Attribution 4.0 Licens BY DOI: 10.19080/APBIJ.2017.01.555572
Your next submission with Juniper Publishers will reach you the below assets

- Quality Editorial service

- Swift Peer Review

- Reprints availability

- E-prints Service

- Manuscript Podcast for convenient understanding

- Global attainment for your research

- Manuscript accessibility in different formats ( Pdf, E-pub, Full Text, Audio)

- Unceasing customer service

Track the below URL for one-step submission https://juniperpublishers.com/online-submission.php 